\title{
FROM SURVEY TO 3D MODELLING TO DIGITAL FABRICATION. A WORKFLOW AIMED AT DOCUMENTING AND TRANSMITTING BUILT HERITAGE
}

\author{
R. Spallone ${ }^{1 *}$, M.C López González ${ }^{2}$, M. Vitali ${ }^{1}$, G. Bertola ${ }^{1}$, F. Natta ${ }^{1}$, F. Ronco ${ }^{1}$ \\ ${ }^{1}$ Dept. of Architecture and Design, Politecnico di Torino, Italy - (roberta.spallone, marco.vitali, giulia.bertola, fabrizio.natta, \\ francesca.ronco)@polito.it \\ ${ }^{2}$ Dept. of Graphic Expression in Architecture, Universitat Politècnica de València, Spain - mlopezg@ega.upv.es
}

\section{Commission II}

KEY WORDS: Metric survey, 3D modelling, Digital fabrication, BH transmission, Baroque vaults, Palazzo Mazzonis.

\begin{abstract}
:
This contribution illustrates the results of research that aims to connect the workflow for knowledge - survey, interpretation, modeling - to the transmission of this knowledge and enhancement of Cultural Heritage by physical models, demonstrating its potential in a "Design for All" perspective.

Palazzo Mazzonis, the current seat of the MAO (Museo d'Arte Orientale), is one of the many buildings in the historic city center of Turin characterized by a particular complex vaulted atrium: it has been investigated through TLS survey tools for the production of two-dimensional drawings (for the detailed representation of architectural features) and three-dimensional models (for the interpretation of the design idea through geometry). The last phase of work aims to translate the interpretative digital models into tactile models for Cultural Heritage transmission, through processes of digital fabrication, with obvious impacts on the visit path inside the museum, also with didactic purposes.
\end{abstract}

\section{INTRODUCTION}

The present proposal is one of the outcomes of an international collaboration for the project "Nuevas tecnologías para el análisis y conservación del patrimonio arquitectónico", funded by the Ministry of Science, Innovation and University of Spain in 2019. This project is focused on the entrances of Baroque palaces in Turin and in particular on the atriums characterized by bricks-made vaults of extraordinary geometric complexity. Although their relevance in the architectural coeval panorama has been highlighted by historians as Pommer (1966) and Norberg-Schultz (1980), they are unknown to the citizens and excluded from touristic routes. For this reason, the workflow of the research, developed as a whole that can be summarized in three main phases - survey, interpretation, modelling - (López González et al., 2020), is now extended to the transmission of knowledge by physical models, demonstrating its potential in a "Design for All" perspective.

\section{AIMS OF THE RESEARCH AND CASE STUDY FEATURES}

The case study faced in this paper, i.e. Palazzo Mazzonis in Turin, seat of the Museo d'Arte Orientale (MAO), adds new meaning to the research developments aimed at communication. In particular, the atrium of the palace houses the Museum's reception area: the first information point on the museum tour (fig. 1).

It is being considered to expose here the plastic models created in this experience, which could also pull together tactile maps for the blind and visually impaired.

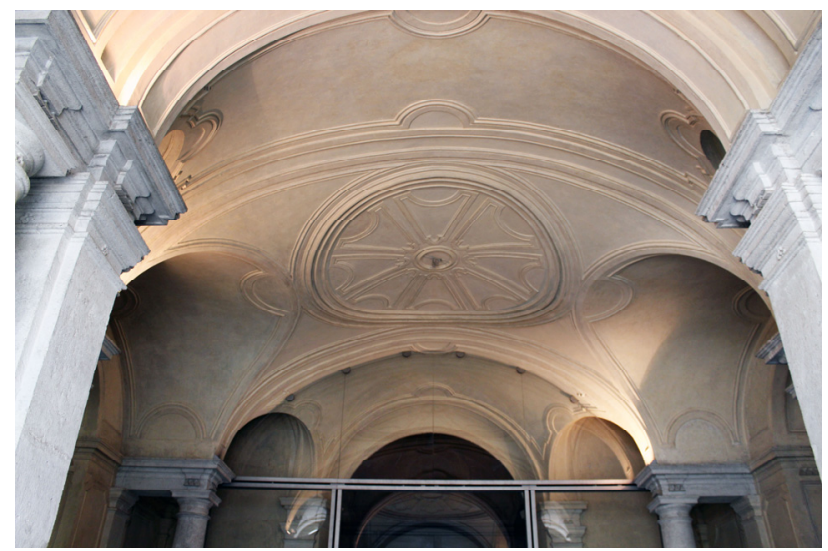

Figure 1. Atrium of Palazzo Mazzonis in Turin, seat of the Museo d'Arte Orientale (MAO). Photo: F. Ronco.

Therefore, the general objective of the research is specified and articulated in the desire to make the museum visitor appreciate the architectural quality of the building that houses the collections. In addition, the variety of users has led to communication choices in the educational field that can overcome cultural, linguistic, and age barriers. The intrinsic tactile potential of the physical models becomes an opportunity to extend to visually impaired users the geometric understanding of the spaces in which they move and creates new synergies of intent with the Museum institution. The particular objective pursued and presented in this work is to make comprehensible the geometric complexity of space, generated in the vaulted system by sophisticated operations of juxtaposition, cutting, and intersection between surfaces that were widespread in the architectural culture of the time.

* Corresponding author 
The historical information about the palace is scarce. The original palace was attested in 1587 (Fondazione Torino Musei, 2015) while the current configuration is supposed to be the result of the enlargement may be designed in 1767 and traditionally attributed to Benedetto Alfieri (Cornaglia, 2003).

In 1845 Count Clemente Solaro della Margherita, owner of the palace, commissioned a survey of the building. The ten plates, representing plans and elevations of the building at a scale of 1:100, are now preserved in the Archivio Storico della Città di Torino.

The palace's atrium and its vaulted system show unique features if compared with well-established models recognized in the historical city center. The main dimensions of the atrium

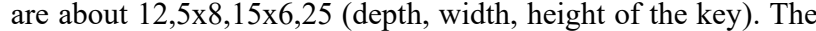
atrium develops from the street to the courtyard and is divided into two main spaces by two pilasters coupled with columns. Coming from the street the first space appears as unitary, although the surface of the vaulted system is interrupted by lintels and arches setting on four columns detached from the perimeter walls. The central field is covered by a barrel vault with lunettes, while the others by portions of sail vaults. Instead, the part overlooking the courtyard is divided into three naves covered by a central sail vault and two lateral groin vaults.

The vaulted system can be analyzed through decomposition by referring to the elementary geometric shapes that make up each of the vault elements and the geometrical operations that allow to recompose them. This process is very similar to that carried out during the construction of one of the physical models (i.e. the model that represents the intrados surface of the vault by substituting solids for voids). The other type of physical model, on the other hand, refers to the method by which, thanks to significant sections of the point cloud, the reconstructive digital model of the design geometries of the vaulted system is created. title should appear centered in bold capital letters, at the top of the first page of the paper with a size of twelve (12) points and single-spacing. Author(s) name(s), affiliation and mailing address should be masked. They will only appear in the final version if the paper is accepted either in the ISPRS Annals or Archives.

\section{STATE OF ART}

As above mentioned, with the present work, we intend to focus on the theme of Digital Fabrication applied to Cultural Heritage, proposing a workflow based on the survey by Laser Scanner, elaboration of the point cloud, and realization of the useful sections for the construction of two types of prototypes, one discretized by sections and one by volumes through the inversion of solid and voids.

In recent years, the development of Digital Fabrication technologies has generated important results in the field of Cultural Heritage and, in particular, of the Built Heritage.

As the researchers of the Centre for Participatory Information Technology (PIT) at Aarhus University argue, Digital Fabrication is not only a design and construction activity oriented to learning prototyping technologies such as 3D Printing, Laser Beam Machine, CNC Milling Machine, but an activity that combines digital fabrication itself, design thinking, collaborative design, and technological innovation to solve specific and complex technical and social challenges (Smith et al., 2015).

The availability of digital scanning, the design and fabrication processes open up possibilities for automation that allow objects to be reproduced in different formats, facilitating access to architectural heritage. Several studies are increasingly proposing multisensory forms of experimentation with architectural artifacts, paying particular attention to both physical and virtual manipulation of objects. These interaction processes, not only create a stronger connection between the individual and the object than mere sight but also have a great benefit from the point of view of heritage accessibility as they meet the different needs of users related to different factors of age, physical, sensory and cognitive abilities, education, culture, and experience (Neumüller et al., 2014).

Within this framework, there are numerous research works focused on the theme of communication of the Built Heritage through the use of real three-dimensional models. Some of them, such as the researches carried out for the imperial cathedral (Kaiserdom) of Königslutter - Germany, the $\mathrm{Ca}^{\prime}$ Venier dei Leoni in Venice - Italy, and the Antioch Gate in the city of Aleppo in Syria, propose a workflow similar to the present work and support the use of digital methodologies in the field of Built Heritage not only to document the current state of architecture but also to review the past transformations it has undergone, preserving and representing it (Kersten et al.,2012; Balletti et.al, 2016; Núñez Andrésa et al., 2012).

Finally, we can mention other studies focused specifically on the issue of accessibility to Cultural Heritage by people with disabilities and particularly visually impaired as the research conducted by the University of Pisa, which aims to make this type of user independent in the understanding of the architectural artifact using low-cost and open-source technologies (Leporini et al., 2020).

\section{SURVEY METHODOLOGY}

As is well-known the preliminary phase of the survey works foresees bibliographical, archival, and historical analyses. At the same time, the realization of on-site eidotypes (i.e. proportioned hand drawings in orthographic projections) allows to know and investigate in advance some visible and knowable features of the building and plan the metric survey through terrestrial laser scanning (TLS). Laser scanners generate massive data in the form of 3D point clouds. It was stressed that a point cloud contains more information than the strictly metric and geometric ones since the devices collect diverse values (i.e. color and reflectance). And therein lies the added value of point clouds as containers of qualitative-topological information. In laser scanners use, it is well known the use of reflectance to discover differences in the documented surface: color, composition, texture, moisture (Puche Fontanilles et al., 2017).

However, before using this device, it is necessary to consider a series of issues which depend on the characteristics of the built heritage to be surveyed: they concern the lighting, the distance up to which the accuracy values of the device can be assumed, and the visibility limitations that require multiple scanning positions.

The metric survey carried out in Palazzo Mazzonis covered the entire ceremonial route: from the atrium to the grand staircase, to the main hall. In this paper, the focus is on the survey of the atrium. Faro Laser Scanner Focus3D x130 has been used. It has a systematic error scope of $\pm 2 \mathrm{~mm}$ of distance in 25 meters which is acceptable for the research. It includes an integrated camera with 70-megapixel non-parallel color overlay so the resulting point clouds acquire a photographic realism. Finally, this laser scanner has an FLS output format that allows reading the point cloud in all processing programs.

In the case study analyzed, the articulation of the spaces and the caesurae generated by free columns and pillars connected by architraves to the perimeter walls requires careful planning of the scanner positions to avoid blind areas. 
11

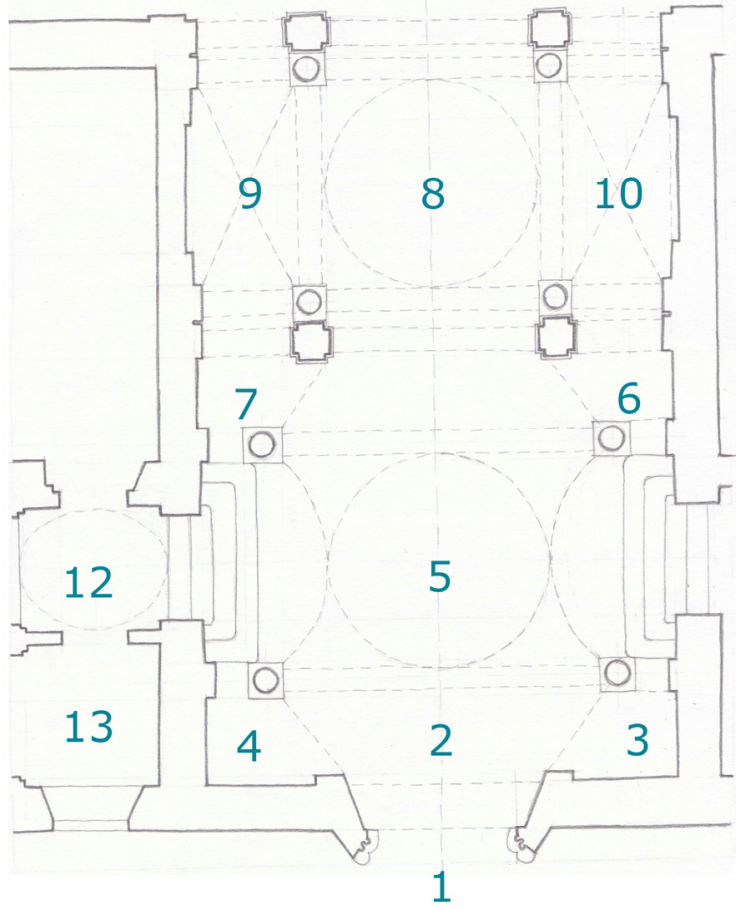

Figure 2. Eidotype of the plan of Palazzo Mazzonis atrium, with the scan positions. Drawing: M. C. López González.

This problem also affects the vaulted system, whose curved surfaces are often hidden by arches and supporting diaphragms. Similarly, moldings, cornices, and stuccoes prevent the visibility of significant edges such as the impost of vaults. Finally, the curvilinear surface of the vaults and the bas-relief decoration give rise to shapes and textures of high reflectivity.

For all these reasons, the position of the scanner and the reference spheres were accurately planned (fig. 2): it was necessary to carry out multiple scans at a short distance, short duration, and great overlap. As mentioned, pillars, arches, and masonry diaphragms produce shaded areas that obstruct the complete vision of parts of the perimeter walls and vaults. The sequence of scanner positions was planned in the following way. The first scanner position was outside the atrium for measuring the thickness of the facade wall. The scans were located at the center of each bay, below the vault, thus ensuring the absence of blind spots and adequate overlap. The location of the reference spheres was planned so that from two consecutive scans at least three spheres were displayed. To ensure the overlap and the absence of blind points it was necessary to scan from 11 positions at a speed of 488,000 points/sec with an approximate duration of 8 minutes each and an average distance between the device positions of $3 \mathrm{~m}$ (fig. 3 ).

\section{PROCESSING}

The scans in .fls format are imported in Autodesk 3D ReCap ${ }^{\mathrm{TM}}$ Pro software. Applying a standard filter to each scan in order to remove weak points and aberrations during the import process. Then the recording and automatic alignment of the point clouds is carried out (the positioning of reference spheres during the survey phase, which are easily identified by the software, is crucial). The subsequent verifications carried out by means of the quality report of the recordings show us the problems of each single cloud and its overlapping with the others; they are

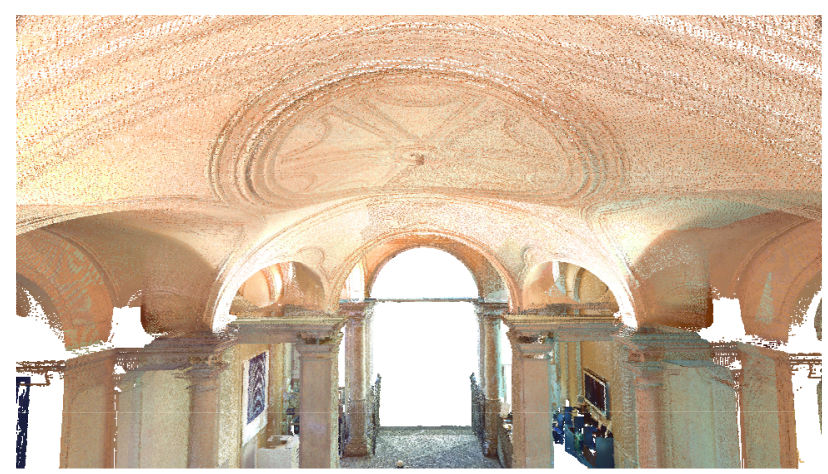

Figure 3. Point cloud of Palazzo Mazzonis atrium. Scan: M. C. López González; processing: F. Natta.

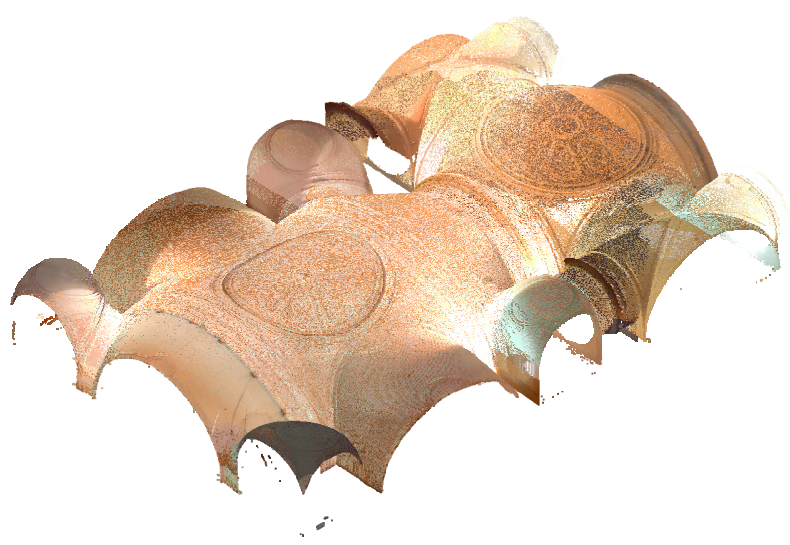

Figure 4. Segmentation of the point cloud of Palazzo Mazzonis atrium: vaulted surface. Scan: M. C. López González; processing: F. Natta.

evaluated and if considered necessary we proceed with manual alignments to improve the entire recording.

Once the processing of the point cloud is complete, cleaning operations of unnecessary points are carried out, as well as the segmentation into parts of the building under study (fig. 4). The focus of the study on the atrium of the palace, is selected and inserted as a link in a native Autodesk ${ }^{\circledR}$ software such as AutoCAD 2021 where it is possible to manage the cloud as a block and carry out all the classic operations of a CAD application.

Before carrying out any other type of operation, it is essential to be aware of what data we want to extract from the point cloud: in this case, points that allow us to reconstruct the curves used to define the surfaces of the vaults. In order to use this data according to geometric constructions, we must have an overall understanding of the intrados surfaces. The sections are then classified to identify the main, secondary and complementary curves according to the complexity of the shape.

The main sections were identified along the perimeter walls, the arches that divide the vaulted system, and the symmetry axes; the secondary sections were extracted at edges between surfaces; the complementary sections are selected to generate a dense orthogonal grid according to the complexity of the shape.

\section{DRAWING AND MODELING}

The drawing and modelling phase concludes the workflow of the whole research. It consists in the creation of architectural drawings through AutoCAD ${ }^{\circledR} 2021$ and three-dimensional models of the ideal geometries underlying the vaulted systems 

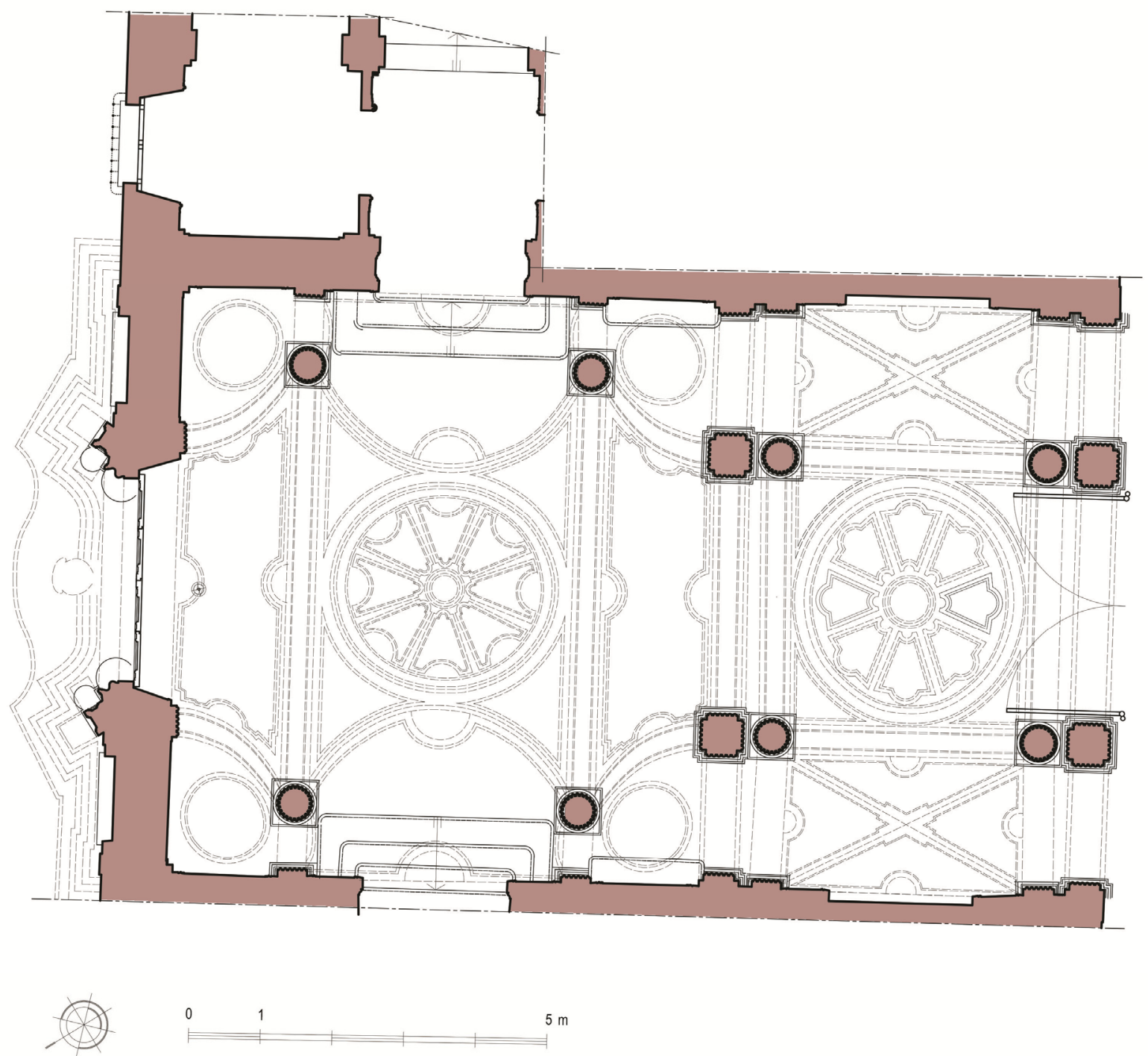

Figure 5. Plan at 1:50 scale of Palazzo Mazzonis atrium. Drawing: M. Vitali

through Rhinoceros ${ }^{\circledR}$ 7. The two phases of two-dimensional representation and 3D modeling testify different and complementary intentions, which on the one hand aim to return the architectural features in detail, according to the scale of representation identified as most suitable for the work, on the other hand, to show the design idea and its connections with geometry

The survey drawings, conceived and produced at a representation scale of 1:50 (graphical error equal to $\pm 1 \mathrm{~cm}$ ) are congruent with the accuracy of the point cloud and constitute the basis for any subsequent investigation or operation aimed at specific interventions on the building. For the construction of the atrium plan (fig. 5), the point cloud, imported in AutoCAD ${ }^{\circledR} 2021$ environment, has been cut from a section plane placed at $120 \mathrm{~cm}$ from the floor level at the entrance door. The slice of the cloud, consisting of points placed at a maximum distance from the ideal section plane of $\pm 1 \mathrm{~cm}$ was vector redrawn.

The longitudinal section (fig. 6) was constructed by identifying the vertical plane passing through the midpoints of the junctions of the axes of the supports (columns and pillars), which testifies to a great regularity of the construction, with a gap between the midpoints and the section plane below $3 \mathrm{~mm}$.

The drawing activity, which constitutes a critical interpretation of the raw survey data, presupposes:

- the recognition and the correct geometrization of the standard elements that constitute components of the architectural orders and moldings of the decorative apparatus,

- the controlled regularization (within the limits of the error allowed by the scale of representation) of the wall layouts,

- the introduction of symbols referring to the codes of representation.

For representing the elements not belonging to the section plane (in projection, as elements over the cutting plane, or in virtual projection, as the vaulted system above the section plane), special cloud slices have been realized.

Unlike survey drawings, three-dimensional modeling is understood by the authors as the digital transposition of the latent geometries of the built architecture. For the construction of the model, the vaulted surface is subdivided into elements organized according to 


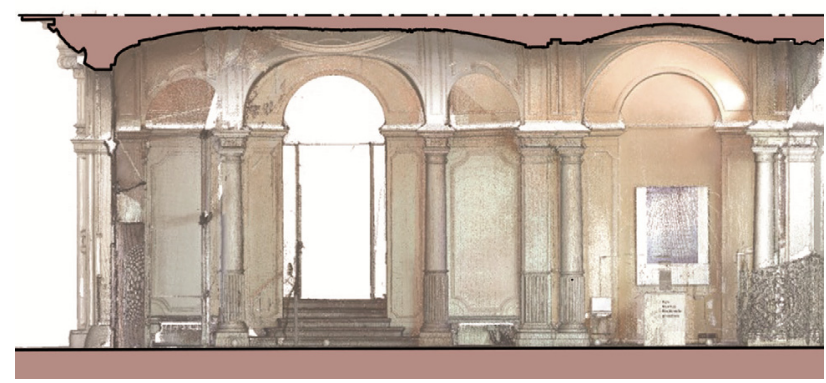

Figure 6. Longitudinal section at 1:50 scale of Palazzo Mazzonis atrium. Drawing: M. Vitali.

a structural and geometrical hierarchy, regularized to respond to rules of symmetry, and distinguished in main, secondary, and angular surfaces.

The modeling process starts from the identification of the distinctive sections of the single surfaces, which derive from the comparison of the sections described in the previous paragraph (main, secondary, and complementary): the sections that are ideally identical because they are symmetrical have been superimposed and re-drawn following the rules of the geometric construction

polycentric curves (with a minimum number of centers - 3 or 5 -, similar to site practices for making centrings). The sections thus obtained were used for the modeling of the double curvature surfaces that make up the individual vaults of the complex system, referring to the main treatise and manual sources (in the local area) on the genesis of the vaulted surfaces (Guarini, 1737; Curioni, 1868): digital construction then proceeds in analogy to the practices of on-site construction as described by the theorists and builders of the time. The obtained model, represented in axonometric exploded view (fig. 7), shows the hierarchical subdivision of the component surfaces of the vaulted system and their geometric interpretation.

From this philological model new opportunities for the research arise, such as the comparison (metric and geometric) through the superimposition of the point cloud.

\section{DIGITAL FABRICATION}

The case study developed in this paper, as said above, adds a new outcome to the workflow: the digital fabrication aimed at producing tactile models for Cultural Heritage transmission (Balletti et al., 2016; Scopigno et al., 2017). In this phase some physical models of the vaults of the atrium showing unique features in comparison with well-established patterns recognized in the historical city center, have been realized. Two types of digital fabricated models have been designed and realized at a scale of 1:50. The aim was to fabricate "illustratives" models, morphologically similar to the object acquired, instead of its exact copy.

Sections have been the key instrument for virtual and physical modelling, discretizing the intrados surface of the vaulted system through its main curves. In the first model these sections have been transformed in real tangible interlocked planar slices, using mesh joinery approach introduced by the research group of CNR - ISTI and the University of Pisa (Cignoni et al., 2014) to fabricate illustrative conceptual models.

Mesh joinery approach is an innovative method to produce models that are approximations of complex shapes, in order to allow efficient manufacturing. For this, the shape is composed of several interconnected planar sections. Such portions can be easily fabricated using any 2D cutting device.

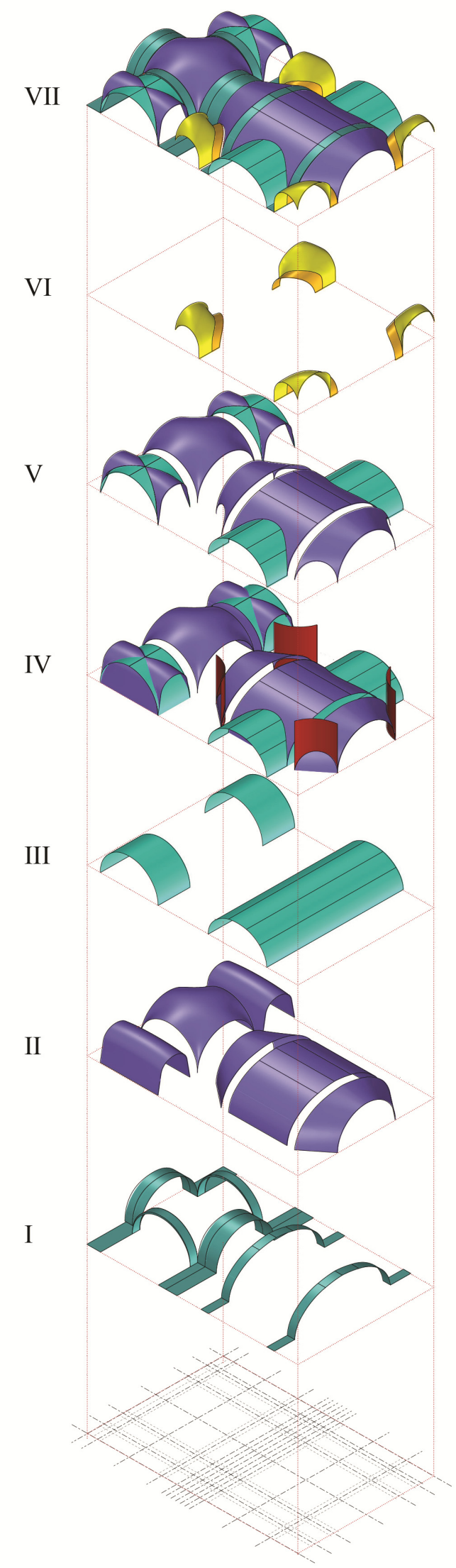

Figure 7. Vault of Palazzo Mazzonis atrium: reconstructive model of the design geometries in axonometric exploded view. Modeling: F. Ronco. 


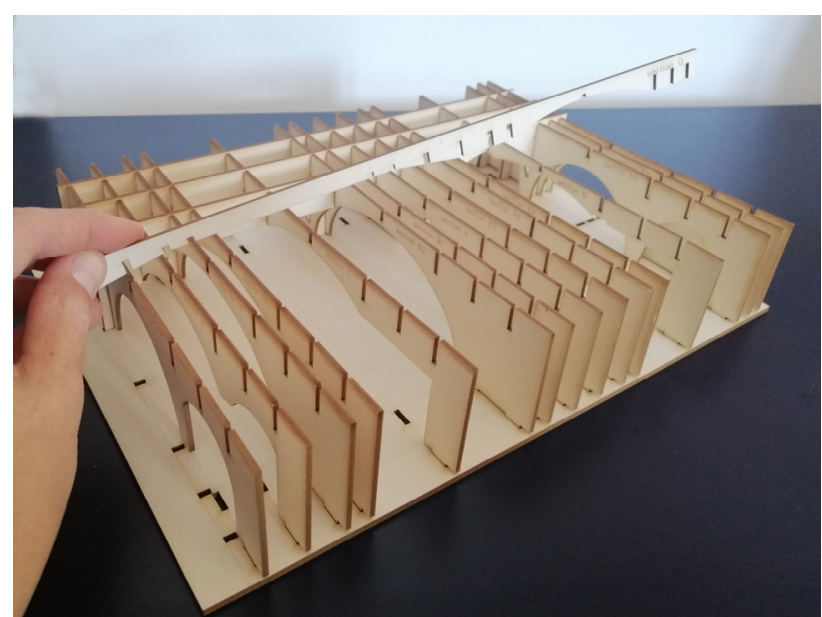

Figure 8. Mesh joinery approach applied to the vault of Palazzo Mazzonis atrium. Digital prototyping: F. Ronco.

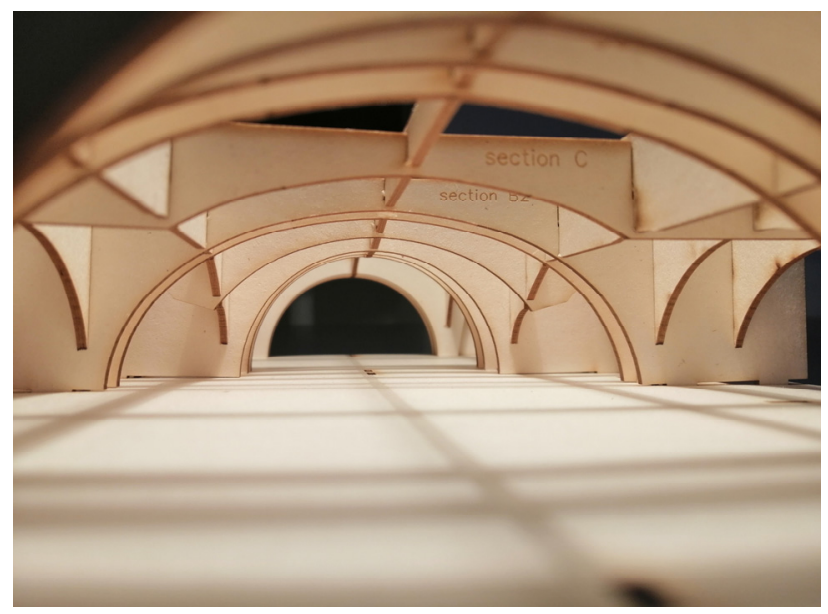

Figure 9. Intradosal view of the physical model of Palazzo Mazzonis atrium. Digital prototyping: F. Ronco.

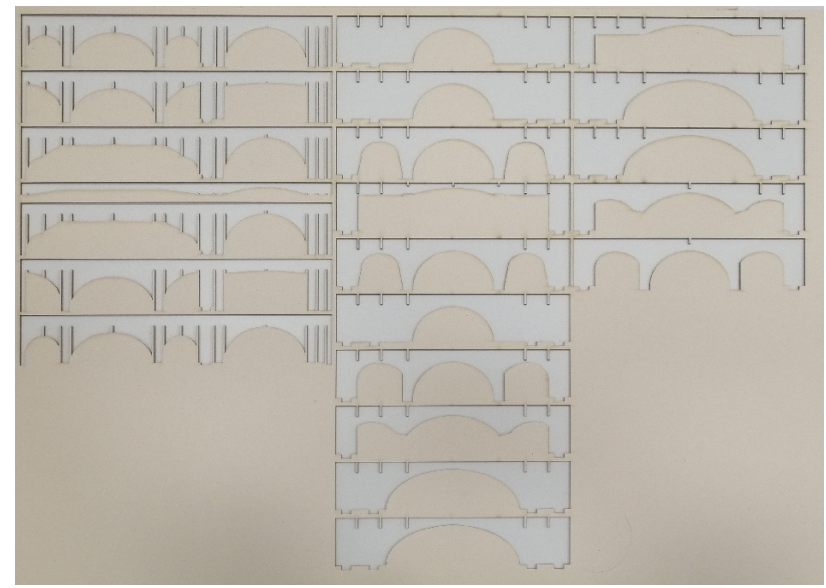

Figure 10. Waste material of the physical model of Palazzo Mazzonis atrium. Digital prototyping: F. Ronco.

In this case the sections obtained from the point cloud, as explained above, have become tangible elements of the real model, consisting of an orthogonal mesh of "fifths" interconnected with each other. Such slices have been fabricated with the 2D cutting device Trotec Speedy $400 \AA$ of ModLab Arch employing relatively inexpensive material (such as cardboard) and then assembled through a sequence of manual operations (fig. 8).

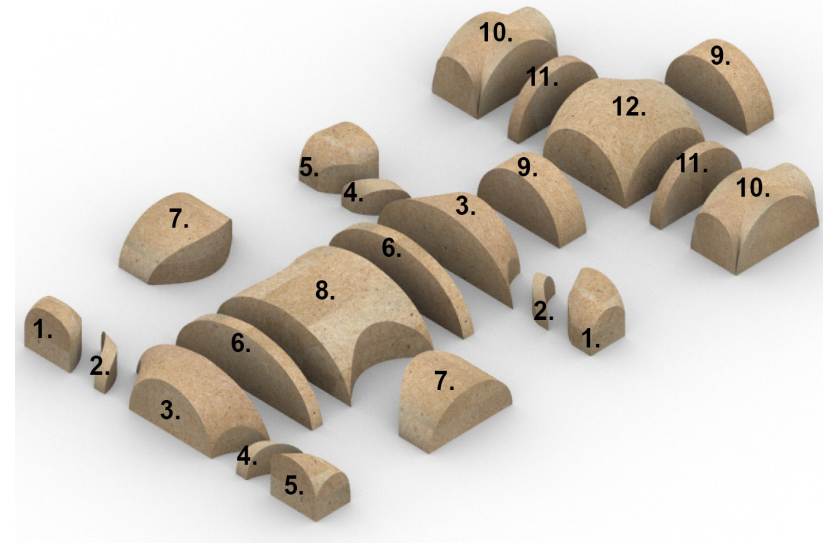

Figure 11. 3D conceptual model for the digital fabrication of the tactile model of the vault of Palazzo Mazzonis atrium.

\section{Modeling: F. Ronco.}

In this model we wanted to emphasize the perception of the vaulted system of the atrium from bottom to top, just like in reality. Therefore, in the design phase of the model, the vaulted system has been inscribed in an ideal parallelepiped that contained it, considering an abundance of $2 \mathrm{~cm}$ on the sides and $5 \mathrm{~mm}$ in height. The next operation was to draw the various slices characterized by a straight profile on three sides and the one corresponding to the profile of the section on the fourth that constitutes the separation between full and empty, between the model and the waste. The next operation was the design of the joints between sections that allow the orthogonal joint. Finally, the pins guarantee the insertion of the section inside the support base that is the materialization of the impost plane of the whole vaulted system (fig. 9). The observation of the waste material of the cutting process (fig. 10) has led to some considerations on the fabrication of a new model with the voids and solids reversed, so that the observer can perceive the curvature of the surface touching the profile from above.

This reflection led to the construction of the second model presented here.

In the second model sections have been used to build the virtual 3D interpretative model with Rhinoceros ${ }^{\circledR} 7$, conceived in the perspective of tactile fruition.

The spaces are represented in negative to obtain a handy object that allows to perceive the intrados surface of the vaults from above.

Also, in this case it has been necessary to make some operations of simplification and subdivision of the model, in order to facilitate its realization with a numerical control milling machine. For this reason, the process is subdivided in successive phases.

The vaulted system consists of ten different types of arches and vaults (fig. 11): trapezial sail vaults (3), arches with curved plan $(2,4)$, angular sail vaults $(1,5)$; arches $(6,9,11)$, lintels, square sail vault (12), and groin vaults (10). Each of these parts, with the exception of the arches, was then subdivided into additional portions.

The main fabrication constraint is the need to try to have at least one flat face to place on the work surface and to avoid moving or rotating the machined piece for further operations. Muntoni et al. (2019), for example, presented their Split and Mill algorithm for computing manufacturable decompositions with 3-axis $\mathrm{CNC}$ milling machines or $3 \mathrm{D}$ printing without external support. 


\begin{tabular}{ccccc}
\hline Setup & Strategy (toolpath) & Machining time [min] & Machining time percentage & Tool \\
\hline Piece 3a & & & & Milling cutter $\varnothing 3 \mathrm{~mm}$ \\
with positive helical \\
cutting edges;
\end{tabular}

Table 1. Piece 3: overview of machining parameters.

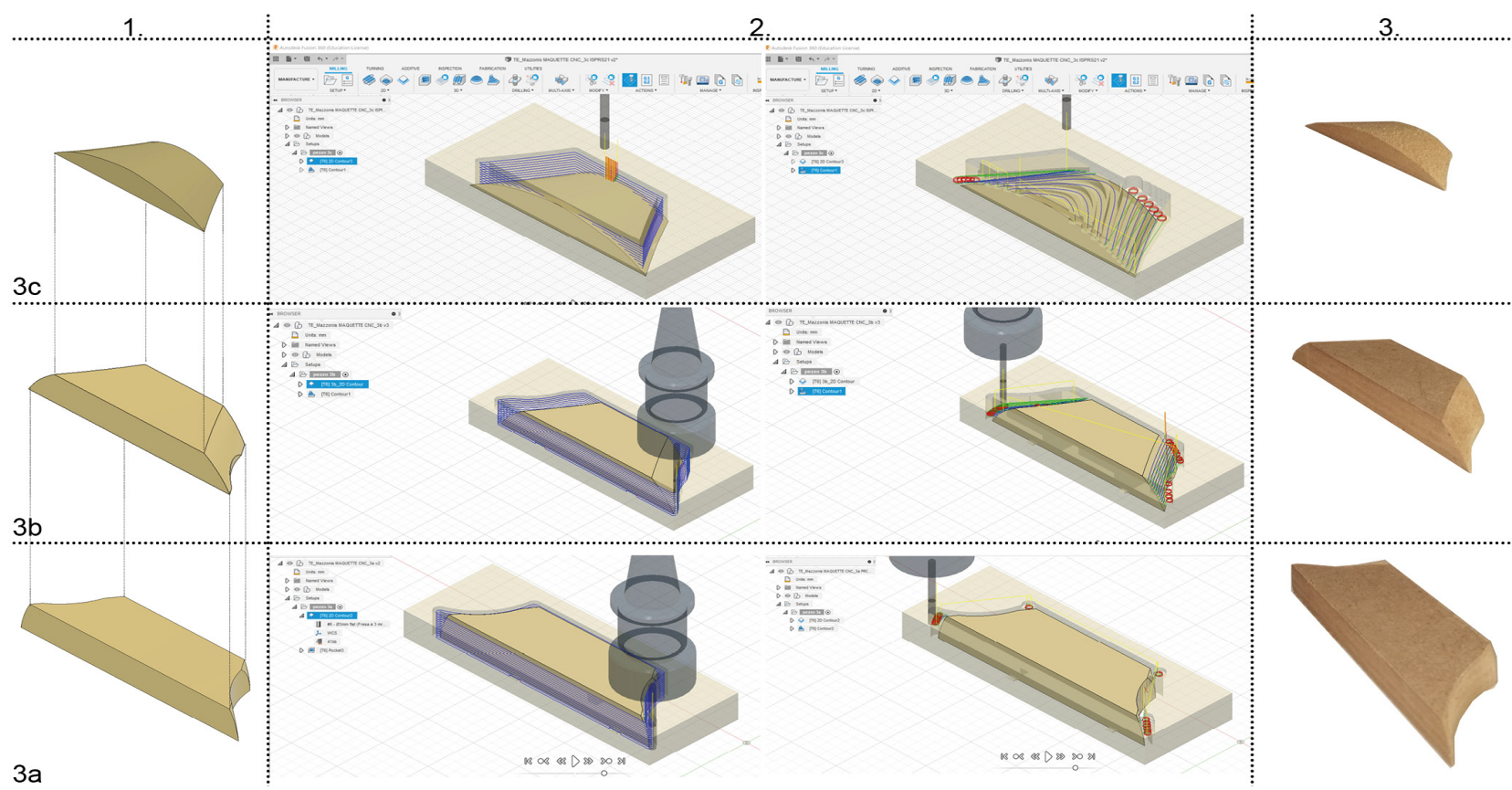

Figure 12. Working steps for the digital fabrication of the tactile model of the vault of Palazzo Mazzonis atrium. Modeling: F.

Ronco.

In this case, these operations were carried out manually, cutting the solids of the various portions with two or three horizontal planes, at a distance of 10,14 or $19 \mathrm{~mm}$ from each other, depending on the thickness of the MDF panel to be used. For every piece was sought the best solution to reduce the waste of material and to optimize the times of production. Pieces 6, 9, 11, differently from other ones, have been proceeded with a simple cutting operation, flipping them on the x-y plane.

The Medium Density Fiberboard (MDF) model has been fabricated with Biemmepi - FP3 CNC milling machine.

Given the chosen material and the small dimensions of the portions, a wood mill with a diameter of $3 \mathrm{~mm}$ was used. The toolpaths have been prepared and verified by simulation features of Autodesk Fusion 360® software. For each piece (excluding 6, 8, 9) two different toolpaths have been set: 2D contour, for the initial cutting operation along the outermost footprint of the piece and 3D contour, for three-dimensional milling operation that follows the three-dimensional surface. We report, for example, the parameters (tab. 1) and the working steps (fig. 12) of the three portions of piece n. 3 (3a, 3b, 3c) and the relative times of fabrication. The next step has been the assembly phase (fig. 13), currently made up of the simple superimposition of parts.
The ultimate goal is to obtain a single block for each of the various portions of the atrium. This will allow to have at the same time, in the assembled configuration, a global perception of the surface of the vaulted system from above and, in the divided one, a deeper understanding of the geometry of the single vaulted portion. The continuum between real and virtual, realized in this case through physical models, is only one of the devices implemented in the research for the transmission of the built heritage. Other solutions, which could have interesting developments on the case study investigated, used AR systems for interaction with the public (Palma et al. 2019)

\section{CONCLUSIONS}

This step of the research shows the use of digital fabrication to a knowledge workflow applied to Built Heritage. The physical models realized aim to communicate the complexity of a Baroque vaulted system and explain its geometric nature. These prototypes could be particularly useful for general didactic purposes. However, the manual mounting can become part of the experience and entertainment for the final purchaser. The fact that the analysed space belongs to a museum means that the didactic purpose can on the one hand be addressed to the 
different targets of exhibition visitors, and on the other hand be specified in tactile experiences for inclusive use.

This paper is the result of the research on complex vaulted systems carried out by the authors. The authors wrote together the paragraphs 1,8, R. Spallone par. 2, G. Bertola par. 3, M. C. López González par. 4, F. Natta par.5, M. Vitali par. 6, F. Ronco 7.

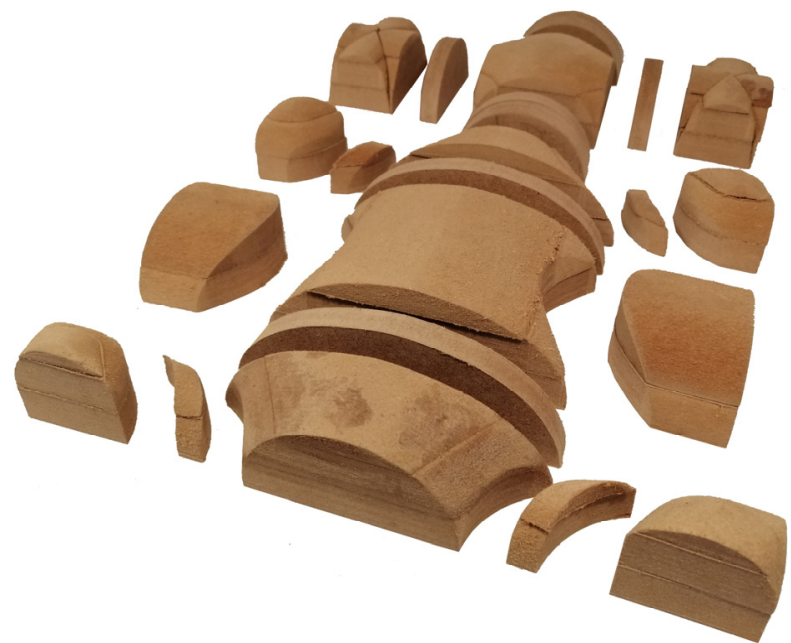

Figure 13. Wooden physical model aimed to tactile experience of the vault of Palazzo Mazzonis atrium. Digital prototyping: F. Ronco.

\section{ACKNOWLEDGEMENTS}

The research was carried out within the framework of an agreement between the Museo d'Arte Orientale and the Politecnico di Torino, aimed to surveying, drawing, digital and physical modeling in order to communicate the architectural features of Palazzo Mazzonis. We would like to thank Dr. Marco Guglielminotti Trivel, Director of the Museum, and Arch. Patrizia Bosio, from Technical and Security Office for having favored the current research.

\section{REFERENCES}

Balletti, C., D’Agnano, F., Guerra, F., Vernier, P., 2016: From Point Cloud to Digital Fabrication: A Tangible Reconstruction of Ca' Venier Dei Leoni, The Guggenheim Museum in Venice. Int. Arch. Photogramm. Remote Sens. Spatial Inf. Sci., III-5, 2016, 43-49. doi.org/10.5194/isprs-annals-III-5-43-2016.

Cignoni, P., Pietroni, N., Malomo, L., Scopigno, R., 2014: Field-aligned mesh joinery. ACM Trans. Graph, 33, 1, 11, January 2014, 11:1-11:12. doi.org/10.1145/2537852.

Cornaglia, P., 2003: Guida ai cortili di Torino. Anteprima, Turin.

Curioni, G., 1868: Geometria pratica applicata all'arte del costruttore. Negro, Turin.

Fondazione Torino Musei, 2015: History and installation. https://www.maotorino.it/it/storia-e-allestimento $\quad(20$ April 2021).

Guarini, G., 1737: Architettura Civile. Gianfrancesco Mairesse, Turin.
Kersten, T., Lindstaedt, M., 2012: Virtual Architectural 3D Model of the Imperial Cathedral (Kaiserdom) of Königslutter, Germany through Terrestrial Laser Scanning. In Ioannides, M.; Fritsch, D.; Leissner, J.; Davies, R.; Remondino, F.; Caffo, R. (eds), EuroMed 2012 - Int. Conference on Cultural Heritage, Springer-Verlag, Berlin, Heidelberg, pp. 201-210. doi.org/10.1007/978-3-642-34234-9_20.

Leporini, B., Rossetti, V., Furfari, F., Pelagatti, S., Quarta, A., 2020: Design Guidelines for an Interactive 3D Model as a Supporting Tool for Exploring a Cultural Site by Visually Impaired and Sighted People. ACM Transactions on Accessible Computing, 13, 3, 9, 1-39. doi.org/10.1145/3399679.

López González, M.C., Spallone, R., Vitali, M., Natta, F., 2020: Baroque Banded Vaults: Surveying and Modeling. The Case Study of a Noble Palace in Turin. Int. Arch. Photogramm. Remote Sens. Spatial Inf. Sci., XLIII-B2-2020, 871-878. dx.doi.org/10.5194/isprs-archives-XLIII-B2-2020-871-2020.

Muntoni, A., Nuvoli, S., Scalasc, A., Tola, A., Malomo, L., Scateni, R., 2019: Mill and Fold: Shape Simplification for Fabrication. Computer \& Graphics, 80, 17-28. doi.org/10.1016/j.cag.2019.03.003.

Neumüller, M., Reichinger, A., Rist, F., Kern, C., 2014: 3D Printing for Cultural Heritage: Preservation, Accessibility, Research and Education. In Ioannides, M., Quak, E. (eds). 3D Research Challenges in Cultural Heritage. Springer, Berlin, Heidelberg, 119-134. doi.org/10.1007/978-3-662-44630-0_9.

Norberg-Schulz, C., 1980: Architettura Tardobarocca. Electa, Milan.

Núñez Andrés, A., Buill Pozueloa, F., Regot Marimónb, J., de Mesa Gisbert, A., 2012: Generation of virtual models of cultural heritage. Journal of Cultural Heritage, 13, Elsevier Masson SAS, 103-106. doi.org/10.1016/j.culher.2011.06.004.

Palma, V., Spallone, R., Vitali, M., 2019: Augmented Turin Baroque Atria: AR Experiences for Enhancing Cultural Heritage. Int. Arch. Photogramm. Remote Sens. Spatial Inf. Sci., XLII/W9, 2019, 557-564. doi.org/10.5194/isprs-archives-XLII2-W9-557-2019.

Pommer, R., 1967: Eighteenth-Century Architecture in Piedmont: The Open Structures of Juvarra, Alfieri and Vittone. New York University Press, New York.

Puche Fontanilles, J., Macias Solé, J.M., Toldrá Domingo, J.M., Solá-Morales, P., 2017: Beyond metrics. Point clouds as semantic graphic expression. EGA Revista de expresión gráfica $\begin{array}{llll}\text { arquitectónica, } & 31, & 22, & 228-237 .\end{array}$ doi.org/10.4995/ega.2017.6781.

Scopigno, R., Cignoni, P., Pietroni, N., Callieri, M. Dellepiane, M., 2017: Digital Fabrication Techniques for Cultural Heritage: A Survey. Computer Graphics Forum, 36, 1, 6-21. doi.org/10.1111/cgf.12781.

Smith, R.C., Iversen, O.S., Hjorth, M., 2015: Design thinking for digital fabrication in education, International Journal of Child-Computer Interaction, 5, Elsevier, 20-28. doi.org/10.1016/j.ijcci.2015.10.002. 